\title{
An Overview of the Role of Solid State Transformer in Grid Connected Wind Farms
}

\author{
Nasiru B. Kadandani ${ }^{1,2}$, Mohamed Dahidah ${ }^{1}$ and Salaheddine Ethni ${ }^{1}$ \\ ${ }^{1}$ School of Engineering, Newcastle University, Newcastle upon Tyne, NE1 7RU, United Kingdom \\ (E-mail: n.b.kadandani2@ncl.ac.uk, mohamed.dahidah@ncl.ac.uk, salaheddine.ethni@ncl.ac.uk) \\ ${ }^{2}$ Department of Electrical Engineering, Bayero University, PMB 3011, Kano, Nigeria \\ (E-mail: nbkadandani.ele@ buk.edu.ng)
}

\begin{abstract}
Grid operators and wind farm vendors often employs multiple circuitries including but not limited to line frequency transformer (LFT), static synchronous compensator (STATCOM) and power factor correction (PFC) devices for grid integration of wind farms. Such components are usually heavy, noisy and causes greenhouse effect. The bulky power transformers for both STATCOM and the wind farm generator hinders this configuration from applications where volume and weight are issues. As such, STATCOM-interfaced wind farm cannot be sited where size, weight, compactness, cable solution, multiport capability and environmental friendliness are critical. This paper demonstrate how solid state transformer (SST) replaces the STATCOM, the bulky transformers, and the additional reactive power compensation devices in grid integration of wind farms thereby providing smaller footprint, compactness and high performance. It is concluded that, SSTinterfaced wind farms can be sited anywhere because of the reduced size, weight, compactness, cable solution, multiport capability and environmental friendliness.
\end{abstract}

Keywords-Solid state transformer (SST); line frequency transformer (LFT); wind farm; wind energy conversion system (WECS); STATCOM.

\section{INTRODUCTION}

Grid integration of renewable energy resources is being considered as a viable solution of producing clean energy required to meet the global demand. However, these renewable energy sources like wind are typically uncontrollable and characterized with power quality issues, as such their penetration at bulk level into the electrical grid can threaten the stability of the interconnected electrical power system. This provides a challenging motivation of developing a safe mode of interfacing wind farms with the power grid. In this regard, an approach based on static synchronous compensator (STATCOM) with line frequency transformer (LFT), a coupling transformer and additional reactive power compensation device like capacitor bank is proposed and demonstrated in [1-5]. In this configuration, the LFT is necessary to interface the low voltage wind generator to the distribution system. However, an LFT in ideal terms represents a simple input-output voltage and current transformation, thus disturbances on one side are fully reflected on the opposite side. Besides, LFT is bulky in size and has heavy weight, thereby occupying large space. Transformer oil can also be harmful when exposed to the environment. Furthermore, LFT core saturation produces harmonics, which results in large inrush currents. Unwanted characteristics on the input side of the system, such as voltage dips, are represented in the output waveform. Harmonics in the output current has an influence on the input. Depending on the transformer connection, the harmonics can propagate to the network or lead to an increase of primary winding losses. On the other hand, the STATCOM has to be fed from a very bulky energy source (like heavy duty capacitor) or energy storage device (like battery) from its input terminal. Apart from volume and weight increase, additional control is required for the state of charge of the energy device to ensure that it does not deplete or overcharge. In case of battery energy storage (BES), the device has the drawback of shorter life cycle and low discharge rate due to chemical reaction rates. Other energy storage devices like superconducting magnetic energy storage system (SMES), energy capacitor system (ECS), or flywheel storage system (FSS) are very expensive. Sequential placement method is required to determine the location for placing the STATCOM to enhance transient stability. Also, an additional damping component is required in order for the STATCOM to improve the wind turbine rotor angle stability and enhance voltage stability by feeding the required reactive power into the grid.

A viable alternative is to replace the STATCOM, the two transformers, and the additional reactive power compensation devices with solid state transformer (SST) as demonstrated in [6]. SST provides direct interface of the wind farm to the power grid while realizing the task of isolation and voltage adaptation. It provides smaller footprint, compactness, high performance, fault tolerance and improved power quality [7]. SST can effectively suppress the voltage fluctuation caused by the transient nature of wind energy without additional reactive power compensator and, as such, may enable large penetration of wind power into the power grid. It offers integrated functionalities of power management, fault management, and energy management [8]. SST functions as circuit breaker, once the power electronics used in the SST are turned off, the flow of electricity will stop and the circuit is interrupted. It employs a high-frequency transformer (HFT) whose size is inversely proportional to its frequency; hence a higher frequency results in a smaller transformer with $80 \%$ lesser volume [9]. The HFT used in SST need no transformer oil, guaranteeing safety from that perspective. SST has much smarter protection approach, able to effectively isolate load and grid side transients, 
including load short circuit conditions and unbalanced input voltages, among others, hence increasing the power quality of the system. It guarantees seamless fault ride through operation during both symmetrical and unsymmetrical faults as per the latest grid codes, it provides instantaneous voltage and current regulation because of the solid state devices and switches, active power transfer, reactive power compensation capability, and voltage-conversion functions and a lot more [10-12]. It has DC port for easy integration of other renewable energy resources and DC microgrid, it has low electromagnetic compatibility concerns and is equipped with fault current management capability on low-voltage and high voltage side.

This paper investigates the role of SST in grid connected wind farms focussing on the major and additional functionalities it offered which were not achieved by STATCOM with LFT. To this end, conventional wind farms based on STATCOM with different types of generators were studied. Further, the paper addresses the challenges of these conventional STATCOM-based wind farms by proposing SSTbased wind farms. In particular, different circuit configurations of SST were presented as well as the role of SST in modern wind farms.

The remaining part of this article is organized as follows: section II presents functional and structural overview of SST, section III presents conventional wind farms based on STATCOM, section IV presents modern wind farms based on SST. In section V, a review of the role of SST in modern wind farms is presented. Lastly section VI concluded the article.

\section{FUNCTIONAL AND STRUCTURAL OVERVIEW OF SST}

\section{A. Structural Overview of SST}

SST is a power electronic based transformer that transforms the line frequency AC voltage into high frequency one which is further stepped up/down by HFT with appreciable decrease in volume and weight, and finally, shaped back into the line frequency voltage to feed the load. Figure 1 shows the structural diagram of SST typically used in wind energy conversion system (WECS). The configuration consists of AC$\mathrm{DC}$ rectifier that regulates the high voltage direct current (HVDC) link, a DC-DC converter that regulates the low voltage direct current (LVDC) link and a DC-AC inverter that produce a regulated low voltage $\mathrm{AC}$ bus [13].

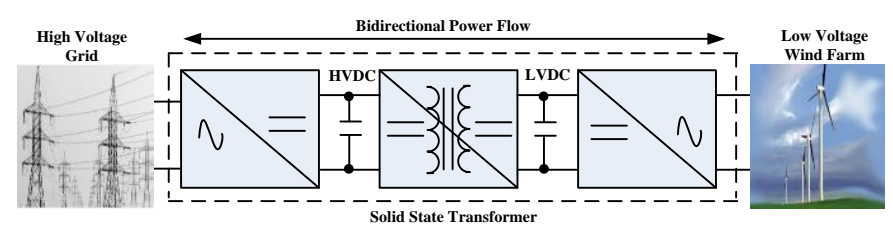

Fig. 1. Structural diagram of SST in WECS

\section{B. Basic Circuit Configurations of SST}

SST can be configured in one of four modes; single-stage SST with no DC link, two-stage SST with a DC link on the secondary side, two-stage SST with a DC link on the primary side, and three-stage SST with a DC link on both primary and secondary sides [14-16]. Figure 2(a) shows the block diagram of single stage configuration and it is typically realised with a full bridge AC-AC converter [17]. It is the simplest topology realised with minimum components. As such, it has higher reliability [18]. However, it lacks DC links, as such it cannot provide reactive power compensation. Figure 2(b) shows a two stage SST with LVDC link. This configuration support distributed energy sources and can provide reactive power support to the grid. Figure 2(c) on the other hand is a two stage SST with HVDC link. The provision of the HVDC link makes this configuration suitable for DC distribution system and in connecting wind farms to the onshore grid. It also support reactive power compensation. Both types of two stage configuration require large switching devices, as such, complex switching methods are required [19]. Figure 2(d) shows a three stage SST. This configuration has high flexibility and superior controllability due to the galvanic isolation provided by the presence of both LVDC and HVDC links [20]. This makes it suitable topology for grid integration of wind farms where reactive power compensation, harmonic filtering, fault isolation and fault ride through capabilities are required.

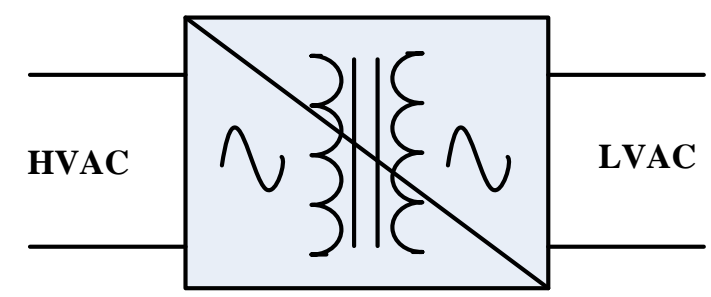

(a)

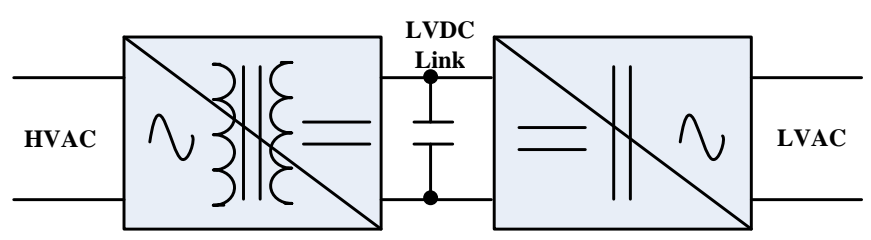

(b)

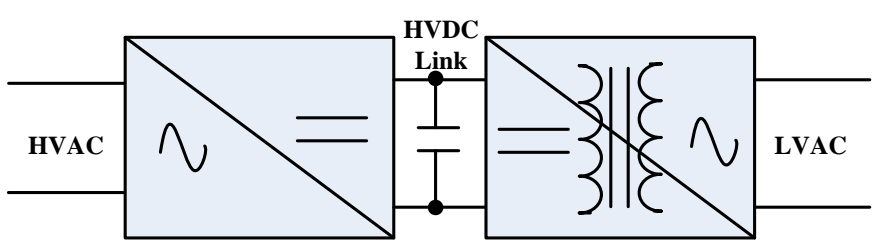

(c)

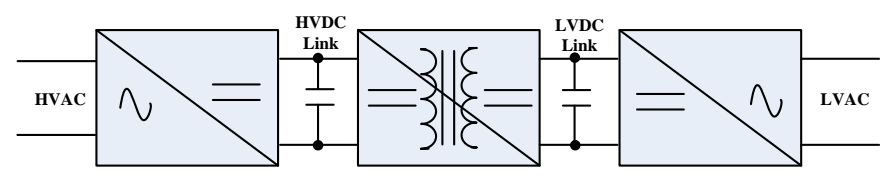

(d)

Fig. 2. Basic circuit configurations of SST, (a) Single stage configuration, (b) Two stage configuration with LVDC link, (c) Two stage configuration with HVDC link, (d) Three stage configuration 


\section{CONVENSIONAL WIND FARMS BASED ON STATCOM}

The techniques for WECS reported in literature are categorized based on the type of generator used. The most common ones are squirrel cage induction generator (SCIG), doubly fed induction generator (DFIG) and directly driven synchronous generator (DDSG). The technique based on SCIG is reported in [21]. The excitation of the SCIG is provided by the high voltage grid. Major features of this configuration as shown in fig. 3(a) include direct connection with the grid, constant rotational speed, provision of soft starters for smooth connection to the high voltage grid, and provision of capacitor banks for reactive power compensation. The technique based on DFIG is reported in [22]. Fig. 3(b) shows the functional block diagram of this configuration whose major features include direct and soft connection of the generator with the grid, and the provision of power electronic converter for speed control and reactive power compensation. The technique based on DDSG is reported in [23]. The major feature of this configuration as shown in fig. 3(c) is the use of full power back-to-back power electronic converter in decoupling the generator completely from the high voltage grid.

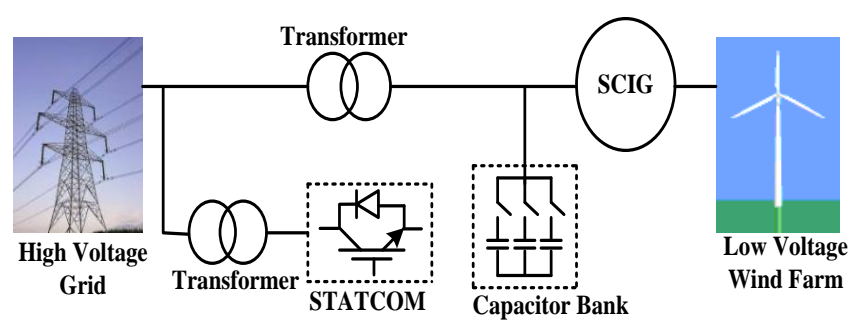

(a)

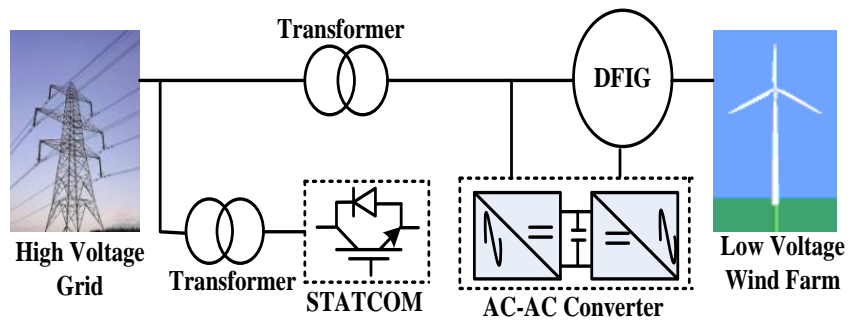

(b)

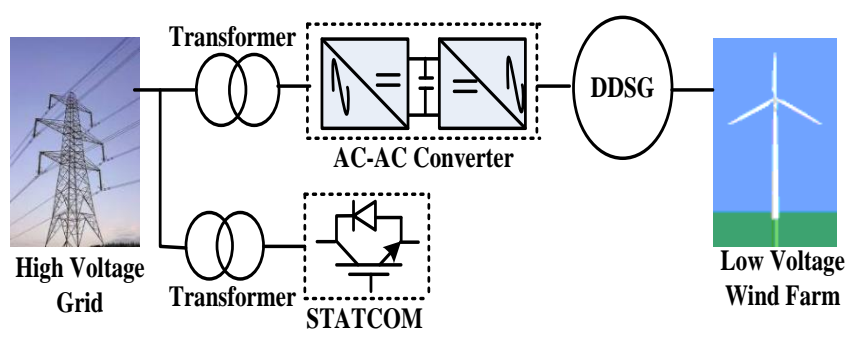

(c)

Fig. 3. Conventional wind farms based on STATCOM, (a) Using SCIG, (b) Using DFIG, (c) Using DDSG

\section{MODERN WIND FARMS BASED ON SST}

In order to ensure smooth and efficient grid integration of wind farms, the SST technology is employed to replace STATCOM, the bulky transformers and the reactive power compensation devices used in the conventional wind farms.

Figure 4 shows the functional diagram of SST in modern wind farms. In particular, fig. 4(a) is the block diagram of SSTbased wind farm with SCIG where the SST replaces the STATCOM, the two transformers, and the capacitor banks used for reactive power compensation thereby providing smaller footprint, compactness and high performance. Fig. 4(b) shows the block diagram of SST-based wind farm with DFIG. In this configuration, the partial back-to-back AC-AC converter is retained whereas the SST replaces the STATCOM, and the two transformers. Fig. 4(c) is the block diagram of SST-based wind farm with DDSG where the SST replaces the STATCOM, the two transformers, and the full power back-toback AC-AC converter.
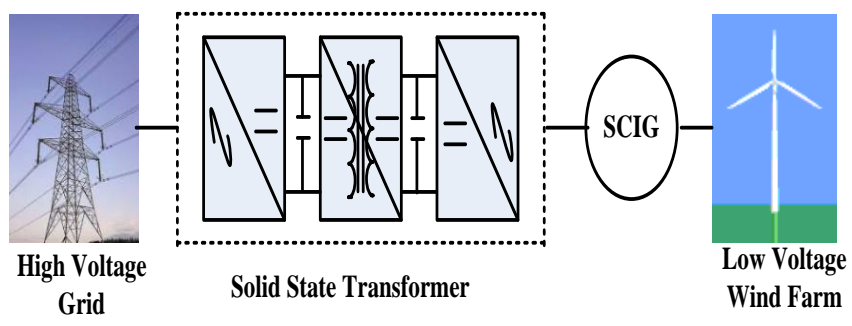

(a)
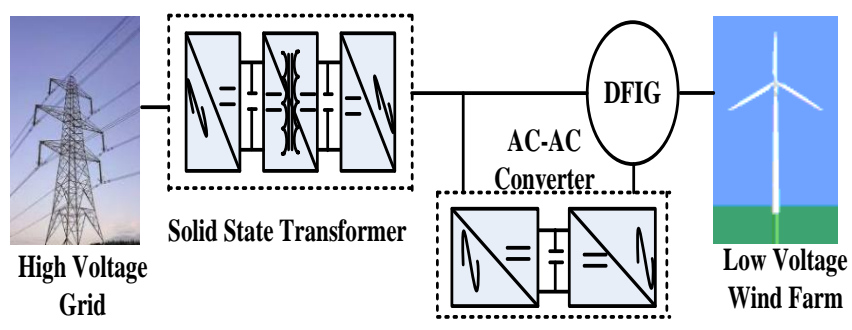

(b)
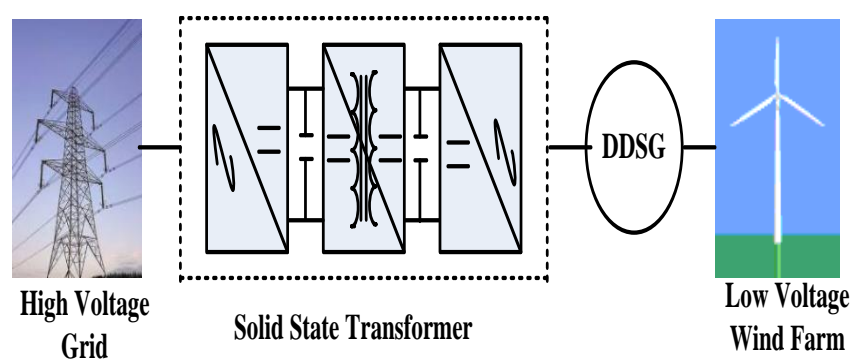

(c)

Fig. 4. Modern wind farms based on SST, (a) Using SCIG, (b) Using DFIG, (c) Using DDSG 


\section{REVIEW Of THE Role Of SST IN MODERN WIND FARMS}

SST is an emerging technology that can replace the bulky LFT in voltage transformation with additional ancillary services to the grid such as reactive power compensation / harmonic filtering, disturbance and fault isolation and many more. SST is also being considered in grid integration of renewable energy sources such as wind, where it can provide a direct substitute for STATCOM, its coupling transformer, the bulky step-up LFT and active power filter (APF). In fact, SST can be used for power quality improvement in grid connected wind farms faster than the conventional FACTS devices.

In [24], the authors compared the performance of a conventional line frequency transformer (LFT) interfaced wind farm (WF) of squirrel cage induction generator (SCIG) SST interfaced WF, also of SCIG type in terms of active power transfer, reactive power compensation, and voltage conversion functionality. Simulation results shows that the SST approach provides better voltage regulation and can fulfil the tasks of active power transfer, reactive power compensation and voltage-step better than LFT. The result also shows that SST can suppress the voltage fluctuations caused by transient nature of wind energy without any additional reactive power compensation device. The simulation result was then validated with a laboratory prototype (a scaled down version). The result confirms that SST can provide power transfer and reactive power compensation.

Researchers in [25] proposed and demonstrate a SST interfaced permanent magnet synchronous generator (PMSG) wind energy conversion system (WECS). A 10 kVA PMSGSST system was considered in the simulation. The results show that the PMSG-SST system is capable of providing a direct interface to the point of interconnection (POI) with the SST, thereby eliminating the need of bulky LFT often used in the conventional STATCOM-interfaced wind energy conversion system.

The study presented in [26] investigated power management strategy on a DC network system consisting of WTs, SST, and DC loads in WECS of PMSG type. Without any energy storage devices (ESD), an autonomous power management strategy based on improved DC bus signalling (DBS) is proposed to achieve system stable operation and power balance under various scenarios, specifically system grid-connected mode, islanding mode, and the mode transition.

In [27], the authors investigated how SST can perform the integrated functions of active power transfer, reactive power compensation, and voltage conversion in wind energy systems. A simulation study for WF driven by SCIG is presented to verify the effectiveness of the proposed system. The result shows that SST can effectively suppress the voltage fluctuations caused by the transient nature of wind energy without additional reactive power compensator and, as such, may enable the large penetration of WF into the power grid. The aforementioned functions of SST in the presented wind energy system were also verified in a single-phase laboratory prototype with scaled-down experiments.
Researchers in [28] investigated the voltage ride through capability of SST based induction wind power generator gridconnected system. System working principle at power flowing forward and backward status were analyzed and the control strategy of each module was designed afterwards. A system simulation model was built and the results shows that the newly designed system is of good working performance. The grid connecting current is sinusoidal and unity power factor control is achieved. Output voltage and DC bus voltage are stable during the operating process. During voltage sag caused by grid faults, energy storage devices connected to the SST discharges to sustain the low-voltage DC bus voltage, enhancing the system low voltage ride through (LVRT) capability.

In [29], the authors presented a backup power conditioning strategy for wind energy-fed voltage source converter HVDC transmission systems. An induction machine (IM) based flywheel energy storage systems (FESS) is integrated to a HVDC system via a solid state transformer (SST). The FESS is integrated to wind farms-fed HVDC transmission system via a two stage SST. The low speed FESS is based on an induction machine (IM) coupled with flywheel. A control strategy of FESS with SST was implemented to improve transient stability, increase power transfer capability from/to the grid with better dynamics to comply with the random variation of wind power and/or step change in grid demand. For this case study, the FESS and the integrating SST ratings were selected as $40 \%$ of HVDC system rating. The simulation results are driven to investigate the dynamics of the system in two scenarios. The first one, the healthy condition, the wind power is assumed to change randomly from 0.6 to $1.4 \mathrm{p}$.u. The FESS stores energy when the WFs generates active power more than the demand (charging mode) and restore energy when the WFs generate active power less than the demand (discharging mode). The fluctuations of wind power are compensated and the grid power is controlled at its required level while the reactive power set at zero achieving UPC at grid side. In the second scenario, during AC fault, a three phase to ground fault is applied to demonstrate the fault ride-through capability of the proposed system.

Researchers in [30] investigated a medium-voltage SSTinterfaced permanent magnet synchronous generator system with integrated active power management and reactive power compensation functions. Specifically, a WECS consisting of wind turbines, SSTs, and dc loads is presented. In addition, a distributed power management algorithm is proposed for a dc network with local wind turbine controls incorporated to achieve a self-contained power-balanced condition without the need for energy storage or communication devices. Scenarios considered include the grid-connected mode, the islanding mode, and the mode transitions. Simulation results are provided to verify the effectiveness of the proposed strategy. In all the cases, the proposed SST-based WECS is found worthy of addressing the high transmission losses and bulky LFT issues associated with the conventional STATCOMbased WECS. They also verified the concept experimentally using a scaled-down laboratory prototype. 


\section{CONCLUSION}

The electrical grid is becoming more complex due to the large penetration of renewable energy sources. In this regard, the SST has been identified as the potential alternative that can be used to achieve smooth and efficient integration of renewable energy sources with the grid. The paper has covered the roles of SST in grid connected wind farms. Structural overview and major circuit configurations of SST were summarized, and its role in grid connected wind farms were presented. It has been demonstrated in the paper that SST can replace STATCOM, two transformers, and additional reactive power compensation devices used in grid integration of wind farms thereby providing smaller footprint, compactness and high performance.

\section{REFERENCES}

[1] C. Han et al., "STATCOM Impact Study on the Integration of a Large Wind Farm into a Weak Loop Power System," IEEE Transactions on Energy Conversion, vol. 23, No. 1, pp. 226-233, 2008.

[2] L. Wang and D. Truong, "Stability Enhancement of DFIG-Based Offshore Wind Farm Fed to a Multi-Machine System Using a STATCOM," IEEE Transactions on Power Systems, vol. 28, No. 3, pp. 2882-2889, 2013.

[3] L. Wang and C. Hsiung, "Dynamic Stability Improvement of an Integrated Grid-Connected Offshore Wind Farm and MarineCurrent Farm Using a STATCOM," IEEE Transactions on Power Systems, vol. 26, No. 2, pp. 690-698, 2011.

[4] W. Qiao, G. K. Venayagamoorthy, and R. G. Harley, "Real-Time Implementation of a STATCOM on a Wind Farm Equipped With Doubly Fed Induction Generators," IEEE Transactions on Industry Applications, vol. 45, No. 1, pp. 98-107, 2009.

[5] S. W. Mohod and M. V. Aware, "A STATCOM-Control Scheme for Grid Connected Wind Energy System for Power Quality Improvement," IEEE Systems Journal, vol. 4, No. 3, pp. 346-352, 2010.

[6] R. Gao, X. She, I. Husain, and A. Q. Huang, "Solid-StateTransformer-Interfaced Permanent Magnet Wind Turbine Distributed Generation System With Power Management Functions," IEEE Transactions on Industry Applications, vol. 53 No. 4, pp. 3849-3861, 2017.

[7] X. She, X. Yu, F. Wang, and A. Q. Huang, "Design and Demonstration of a 3.6-kV-120-V/10-kVA Solid-State Transformer for Smart Grid Application," IEEE Transactions on Power Electronics, vol. 29, No. 8, pp. 3982-3996, 2014.

[8] A. Q. Huang, "Medium-Voltage Solid-State Transformer: Technology for a Smarter and Resilient Grid," IEEE Industrial Electronics Magazine, vol. 10, No. 3, pp. 29-42, 2016.

[9] J. E. Huber and J. W. Kolar, "Volume/Weight/Cost Comparison of a $1 \mathrm{MVA} 10 \mathrm{kV} / 400 \mathrm{~V}$ Solid-State Against a Conventional LowFrequency Distribution Transformer," Proceedings of IEEE Energy Conversion Congress and Exposition (ECCE), pp. 45454552, 2014.

[10] A. Rehman and M. Ashraf, " Design and Analysis of PWM Inverter for $100 \mathrm{KVA}$ Solid State Transformer in a Distribution System," IEEE Access, vol. 7, pp. 140152-140168, 2019.

[11] X. Zhang, Y. Xu, Y. Long, S. Xu, and A. Siddique, "HybridFrequency Cascaded Full-Bridge Solid-State Transformer," IEEE Access, vol. 7, pp. 22118-22132, 2019.

[12] Z. Qu, Y. Yao, Y. Wang, C. Zhang, Z. Chong, and A. Abu-Siada, "A Novel Unbalance Compensation Method for Distribution SolidState Transformer Based on Reduced Order Generalized Integrator," IEEE Access, vol. 7, pp. 108593-108603, 2019.
N. B. Kadandani, M. Dahidah, S. Ethni, and M. A. Alharbi, "Overloading Scenario in Solid State Transformer," Proceedings of
2020 IEEE 11th International Renewable Energy Congress (IREC), Hammamet, Tunisia, pp. 1-6, 2020.

[14] N. B. Kadandani, M. Dahidah, S. Ethni, and J. Yu, "Solid State Transformer: An Overview of Circuit Configurations and Applications," 15th IET International Conference on AC and DC Power Transmission (ACDC 2019), Coventry, UK, pp. 1-6, 2019.

[15] S. Falcones, X. Mao, and R. Ayyanar, "Topology Comparison for Solid State Transformer Implementation," Proceedings of IEEE Power and Energy General Meeting, pp. 1-8, 2010.

[16] J. E. Huber and J. W. Kolar, "Solid-State Transformers: On the Origins and Evolution of Key Concepts," IEEE Industrial Electronic Magazine, vol. 10, No. 3, pp. 19-28, 2016.

[17] H. Qin and J. W. Kimball, "Solid-State Transformer Architecture Using ACAC Dual-Active-Bridge Converter," IEEE Transactions on Industrial Electronics, vol. 60, No. 9, pp. 3720-3730, 2013.

[18] H. Qin and J. W. Kimball, "A Comparative Efficiency Study of Silicon Based Solid State Transformers," Proceedings of IEEE Energy Conversion Congress and Exposition (ECCE), pp. 14581463, 2010.

[19] H. Chen, A. Prasai, and D. Divan, "Dyna-C: A Minimal Topology for Bidirectional Solid-State Transformers," IEEE Transactions on Power Electronics, vol. 33.No. 2, pp. 995-1005, 2017.

[20] D. Das and C. Kumar, "Operation and Control of Smart Transformer Based Distribution Grid in a Microgrid System," Proceedings of the 2017 National Power Electronics Conference (NPEC), Pune, pp. 135-140, 2017.

[21] A. E. Leon, M. F. Farias, P. E. Battaiotto, J.A.Solsona, and M. I Valla, "Control Strategy of DVR to Improve Stability in Wind Farms using Squirrel-Cage Induction Generators," IEEE Transactions on Power System, vol. 26, No. 3, pp. 1609-1617, 2011.

[22] J. Zou, C. Peng, H. Xu, and Y. Yan, "A Fuzzy Clustering Algorithm-Based Dynamic Equivalent Modeling Method for Wind Farm With DFIG," IEEE Transactions on Energy Conversion, vol. 30, No. 4, pp. 1329-1337, 2015.

[23] H. Huang, C. Mao, J. Lu, and D. Wang, "Small-Signal Modelling and Analysis of Wind Turbine with Direct Drive Permanen Magnet Synchronous Generator Connected to Power Grid," IET Renewable Power Generation vol. 6, Issue 1, pp. 48 - 58, 2012.

[24] X. She, A. Q. Huang, and R. Burgos, "Review of Solid-State Transformer Technologies and Their Application in Power Distribution Systems," IEEE Journal of Emerging and Selected Topics in Power Electronics, vol. 1, no. 3, pp. 186-198, 2013.

[25] R. Gao, I. Husain, F. Wang, and A. Q. Huang, "Solid-State Transformer Interfaced PMSG Wind Energy Conversion System," Proceedings of IEEE Applied Power Electronics Conference and Exposition (APEC), pp. 1310-1317, 2015.

[26] R. Gao, I. Husain, and A. Q. Huang, "An Autonomous Power Management Strategy Based on DC Bus Signalling for Solid-State Transformer Interfaced PMSG Wind Energy Conversion System," Proceedings of IEEE Applied Power Electronics Conference and Exposition (APEC), pp. 3383-3388, 2016

[27] X. She, A. Q. Huang, F. Wang, and R. Burgos, "Wind Energy System with Integrated Functions of Active Power Transfer, Reactive Power Compensation, and Voltage Conversion," IEEE Transactions on Industrial Electronics, vol. 60, no. 10, pp. 4512 4524, 2013.

[28] Q. Wang and D. Liang, "Characteristics Research of Wind Power Generator Interfaced to Grid via Solid State Transformer with Energy Storage Device," Proceedings of the 10th International Conference on Ecological Vehicles and Renewable Energies 2015.

[29] R. G. Gadelraba, M. S. Hamad, A. S. Abdel-Khalik, and A. E. Zawawi, "Wind Farms-Fed HVDC System Power Profile Enhancement Using Solid State Transformer Based Flywhee Energy Storage System," Elsevier Journal of Energy Storage, vol. 4, pp. 145-155, 2015.

[30] R. Gao, X. She, I. Husain, and A. Q. Huang, "Solid-StateTransformer-Interfaced Permanent Magnet Wind Turbine Distributed Generation System with Power Managemen Functions," IEEE Transactions on Industry Applications, vol. 53 no. 4, pp. 3849-3861, 2017. 